\title{
US issues new guidelines as mammography debate continues
}

Deborah Josefson Nebraska

US health officials have released new clinical guidelines backing routine mammography for women aged 40 and over in the wake of growing controversy over the value of such testing in reducing deaths from breast cancer.

Although it is widely accepted that screening mammography leads to earlier detection of breast cancer, questions have been raised over whether such early detection actually translates into greater survival, and these have led to a heated media debate in the United States (16 February, p 432).

A media debate began in January, when the Physicians Data Query screening and prevention editorial board, an independent panel of US medical experts that advises the National Cancer Institute, concluded that there was insufficient evidence to show that mammography reduced breast cancer mortality (2 February, p 255).

The board's statements followed a Danish meta-analysis published in the Lancet (2000;355:129-34) that concluded that screening mammography failed to affect breast cancer survival. A 1999 Swedish study found no decrease in breast cancer mortality in Sweden despite routine screening mammography in that country since 1985 (Lakartidningen 1996;96:904-13).

The latest recommendations, which support mammography, come from the US Preventive Services Task Force. They are based on a meta-analysis of eight randomised control trials with 11-20 years of follow up published since 1996. They found methodological errors in each of the trials investigated but rated only one of the trials as "poor" in quality of evidence. They concluded that the flaws in the studies were unlikely to negate the "reasonably consistent and significant mortality reductions observed in these trials."

Four of those studies evaluated mammography alone, and four evaluated the efficacy of mammography with clinical breast examinations in increasing breast cancer survival. On the basis of these analyses, the task force endorsed screening mammography every one to two years for women aged 40 and older. This is a more stringent recommendation than their last recommendation, issued in 1996, which backed screening mammography starting at age 50 .

The task force acknowledged that mammography screening carries inherent risks, such as those of false positives leading to unnecessary surgery and anxiety, but it found that screening mammography could reduce a woman's risk of dying of breast cancer by about $20 \%$.

Richard Winder, deputy national coordinator of the NHS

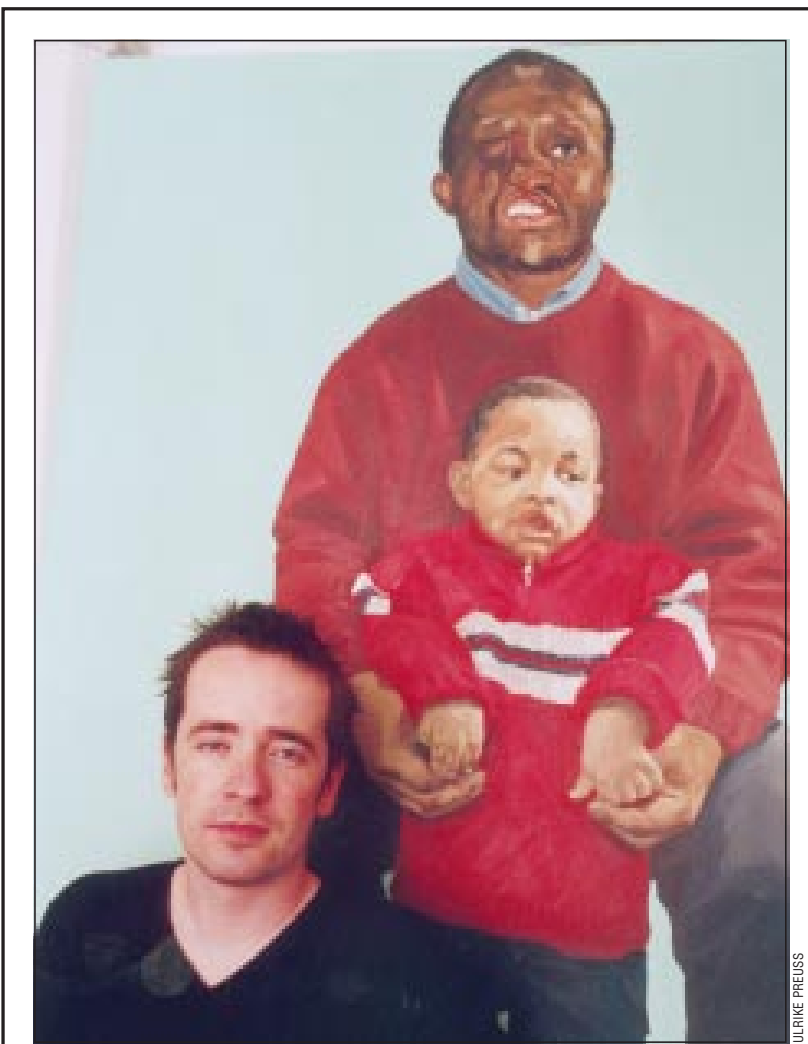

This portrait of Henry $\mathrm{E}$ and his son Jerry is one of a series of paintings by Mark Gilbert (also pictured) of patients who have had facial surgery. The exhibition, organised by the charity Saving Faces, is at the National Portrait Gallery, London, until 21 April.

Cancer Screening Programmes, said that his organisation would like to see the evidence that led to the task force's recommendation to screen women from the age of 40.

"The NHS Breast Screening Programme has always been based on sound research evidence. We constantly review and examine the appropriateness of screening women under 50 and whether there is a need to reduce the present screening interval," he explained. There were currently two trials examining both these issues; one would report shortly and the other would report in 2005 , he added.

\section{First cases of type 2 diabetes found in white UK teenagers}

\author{
Owen Dyer London
}

The trend towards obesity in British children has produced the country's first recognised cases of type 2 diabetes in white adolescents. The illness has been diagnosed in three girls aged from 13 to 15 and a boy aged 15 , according to an article in the journal Archives of Disease in Childhood (2002;86:207-8).
The children, who were referred to treatment centres in Bristol and Southampton, were all clinically obese. Type 2 diabetes has already been noted in children of Asian and African origin, but the white population seems less susceptible to the disease.

Dr Julian Shield, one of the authors, fears that children are unlikely to be diagnosed before damage has occurred to the pancreas. "This phenomenon is likely to become increasingly common," he said. "It is essential that clinicians appreciate the risk of clinical and unrecognised type 2 diabetes associated with obesity in white children as well as those from high risk populations, as early investigation and treatment may delay the onset of complications."

Dr Shield warned that an earlier age of onset is liable to result in a higher rate of complications such as high blood pressure and blindness. He predicts that the incidence will rise in parallel with the growing rate of childhood obesity, placing an increasing strain on the health system. In the year 2000, according to Diabetes UK, the NHS spent $£ 5.2 \mathrm{bn}$ (\$7.5bn; €8.3bn) treating diabetes and its complications-which represents $9 \%$ of the healthcare budget.

Obesity rates have doubled among British children since 1982, and tripled in adults. Professor Edwin Gale, a diabetes expert at Southmead Hospital in Bristol, said that the disease is developing at earlier ages throughout the industrialised world. "Traditionally, the median age at diagnosis is about 60 , but the entire age distribution curve is shifting to the left," he said. "The most extreme scenario is in the United States, where the first cases of type 2 diabetes in white children aged under 10 are now being reported." According to US research, type 2 diabetes now accounts for $30 \%$ of all new cases of diabetes diagnosed in American teenagers (Diabetes Care 1999; 22:345-54).

The European Association for the Study of Diabetes predicts that the number of new cases of diabetes worldwide will double to 270 million people by 2010, of whom four million will be British. 